\title{
Theoretical modelling of slurry erosive wear testing of HVOF thermally sprayed Inconel-Titania coatings
}

\author{
Sekhar $\mathrm{N}^{1}$, Krishna Mohan $\mathrm{M}^{2^{\star}}$, Bhavish N. Reddy ${ }^{2}$ and T. Lakshminarayana Reddy ${ }^{2}$ \\ ${ }^{1}$ Research Scholar (Ph.D), PESIT, R \& D Centre, Bangalore -560085, India \\ ${ }^{2}$ Department of mechanical engineering, PESIT, Bangalore-560085, India \\ krishnamohan1992@gmail.com
}

\begin{abstract}
Material loss due to slurry erosion is a serious problem in many industrial applications like hydraulic turbines, slurry pumps, pipe lines, etc. where the ideal choice of engineering materials is a real challenge. Lightweight aluminum alloys are finding wide applications in the field of aerospace automobile, defence, etc. due to improved physical, mechanical and tribology properties. HVOF (High velocity oxy fuel) Sprayed coatings provide protection against corrosion, erosion and wear. Inconel - 718 is a metallic coating which has good wear and erosion resistance. This was sprayed on to mild steel substrate and then subjected to slurry erosive wear tests. It is observed that the slurry wear rates of mild steel decreased on coating the substrate material with Inconel - 718. The tests were conducted in a slurry erosive wear tester at varying spindle speeds $(500-1500 \mathrm{rpm})$ at different intervals of time. The wear loss was recorded experimentally compared with theoretical values and graphs are plotted to check accuracy. For this comparison, various parameters such as impinging particle size, velocity of solid particles, concentration of slurry bath, hardness of mild steel, time are correlated to obtain a theoretical formulation. A non-dimensional analysis is also done to reduce the number of parameters influencing the wear rate.
\end{abstract}

Keywords: Wear, Abrasion, Slurry erosion, High velocity oxy fuel coating, Inconel-718, Titania

Introduction

Slurry erosion can be defined as a type of wear or loss of material experienced by a component, when exposed to high velocity stream of slurry mixture of solid particles in a liquid, usually water. It is serious problem in many engineering applications. When the components are entrained in such environments, the design life of the component is greatly reduced, resulting in huge economic losses. Erosive wear is a complex phenomenon as it is affected by too many factors such as:

1.Mechanical properties such as hardness and Microstructure

2.Physical property like temperature.

3. Operating parameters such as Impact angle, Speed of solid particles, particle size and shape, slurry concentration , duration etc.

4. Environmental parameters such as relative humidity etc.

\section{Experiment}

Material

For the present investigation mild steel is chosen as the target material owing to its durability, low cost and less brittle nature. The raw material is in the form of flat plates that are later machined to $40^{*} 8^{*} 8 \mathrm{~mm}$ size cuboids. Particle size and coating thickness analysis

The size of impinging particles used affects the rate of erosion. This is known as 'particle size effect'. Erosion rate decreases with decrease in particle size and causes significant changes to slurry flow conditions (Clarke et al., 2001). The size of sand particles varies from $100-600$ microns. In the present case, the precise sizes are 312 and 425 microns. The increase in coating thickness decreases the erosion rate due to low porosity(approx $1 \%)$. The Inconel-Titania mixture is HVOF coated with thickness varying from $50-200$ microns in steps of 50 microns

\section{Hardness}

The hardness of the coating as well as silica particles in slurry affects the wear rate. The hardness of silica was higher than that of mild steel and coating .(John Evans Miler, issue 946). The Vickers hardness number (VHN) of Inconel is taken as 360 and that of silica is taken as $520 \mathrm{VHN}$.

\section{Time duration as varying parameter}

In this experiment, the comparison by taking time as a parameter and without taking it as a parameter is done on $100 \mu$ Inconel. The percentage error decreased from $24 \%$ to $18 \%$ at the peak.

\section{Slurry erosion test}

Slurry erosion tests were carried on polished samples (HVOF coated) of size $8 \mathrm{~mm}$ thick, $8 \mathrm{~mm}$ width and 40 $\mathrm{mm}$ length at room temperature $\left(32^{\circ} \mathrm{C}\right)$. The samples were thoroughly cleaned in acetone and weighed using an electronic microbalance before and after the wear tests. The accuracy of electronic balance is $0.1 \mathrm{mg}$. The apparatus consists of six spindles connected to an electronic motor with the maximum speed of $1500 \mathrm{rpm}$ using a belt drive. The test samples were fixed on each spindle with the help of a screw. All the samples were dipped into slurry pot made of stainless steel. The slurry was prepared by mixing $3.5 \%$ of sodium chloride $(\mathrm{NaCl})$ and silica sand with distilled water. The studies were carried out at different sand concentration (10-40\%), varying rotational speed $(500-1500 \mathrm{rpm})$ at different time durations (3-25 hours) and varying impinging particle size (300-425 $\mu \mathrm{m})$. After the test, specimens were dried and cleaned using acetone before measuring weight loss.
Sekhar et al. Indian J.Sci.Technol. 


\section{Results and discussions}

Fig. 1 shows the microstructure of low carbon steel or mild steel. It contains about $0.1 \%$ carbon by weight, alloyed with iron. It has two major constituents, ferrite and pearlite. The light coloured region of the microstructure is the ferrite (Ernest John Teichert, 1944).

Fig. 1. Microstructure of mild steel base material

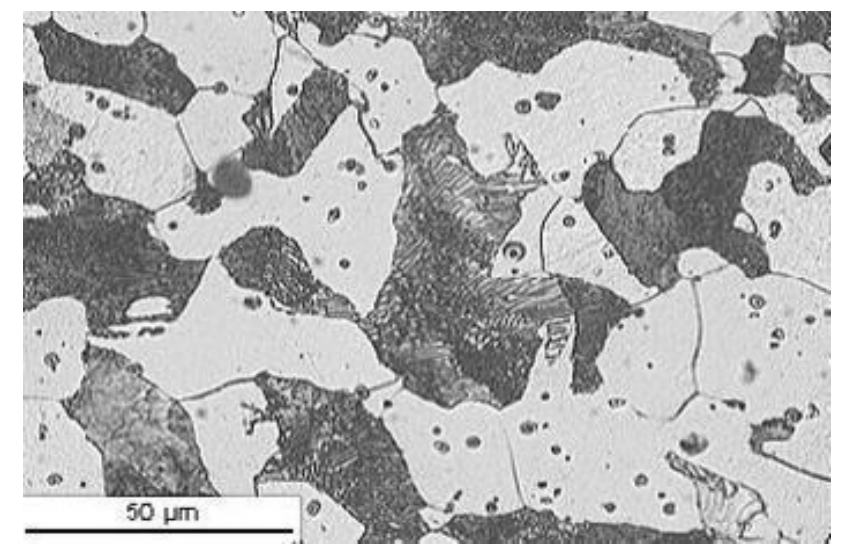

Fig. 2. Microstructure of Inconel 718 material

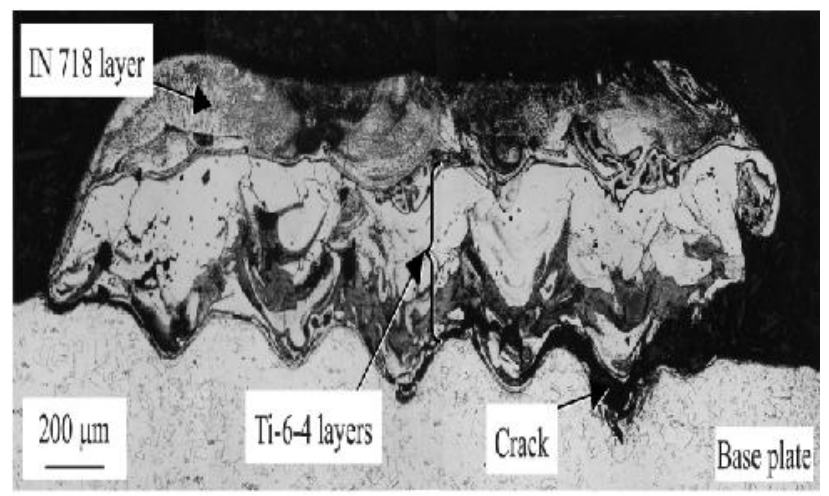

Fig. 3 (a). Effect of coating thickness for rotational speed-500rpm

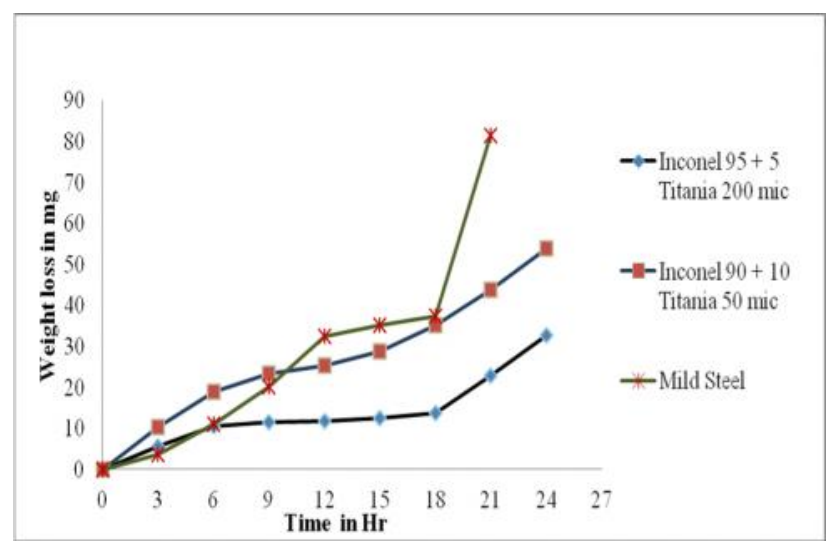

The grain boundaries between the ferrite grains can be seen clearly. The dark regions are the pearlite. This can be seen as a wormy texture. It is made up from mixture of ferrite and iron carbide. The small spots between the ferrite grains are the inclusions or impurities such as oxides or sulphides. During slurry erosive wear testing, the slurry particles impinges on this base material and results in wear loss. This can be reduced to a great extent by reducing the grain size and by decreasing the amount of pearlite. This improves the strength, ductility and toughness of steel. The mild steel must be protected from chemical attacks, as this can result in inclusions between the grains which in turn affect the toughness of the material.

\section{Properties of Inconel 718}

Inconel 718 is a Nickel-Chromium alloy being precipitation hardenable and having high creep-rupture strength at high temperatures to about $700^{\circ} \mathrm{C}$ (Machinability of Inconel , 1997) shown in Fig. 2. The important properties of Inconel 718 are shown in Table 1. Slurry erosive wear results on coated mild steel for 500 rpm

Table 1. Properties of Inconel 718

\begin{tabular}{|c|c|}
\hline Melting point & $1336^{\circ} \mathrm{C}$ \\
\hline Density & $8.19 \mathrm{~g} / \mathrm{cm}^{3}$ \\
\hline Modulus of elasticity & $204.9 \mathrm{KN} / \mathrm{mm}^{2}$ \\
\hline
\end{tabular}

The weight loss was measured at intervals of 3 hours upto 21 hours. At the end of 21 hours, the overall weight loss was determined as follows:

- For Inconel $95 \%+5 \%$ titania $200 \mu$ (slurry is $35 \mathrm{gNacl}+100 \mathrm{~g}$ silica+1litre water), there was $0.16 \%$ weight loss.

- For Inconel $90 \%+10 \%$ titania $50 \mu$ (slurry is $35 \mathrm{gNacl}+100 \mathrm{~g}$ silica+1litre water), there was $0.22 \%$ weight loss.

- For Mild Steel (without any coatings) - (slurry is $35 \mathrm{gNacl}+100 \mathrm{~g}$ silica+1litre water), there was $0.4 \%$ weight loss.

Slurry erosive wear results on coated mild steel for 1000 rpm

The weight loss was measured at intervals of 3 hours upto 18 hours. At the end of 18 hours, the overall weight losses are as follows:

- For $100 \mu$ Inconel (slurry is $35 \mathrm{~g} \mathrm{NaCl}+100 \mathrm{~g}$ silica sand +1 litre water), there was $0.11 \%$ weight loss.

- For $200 \mu$ Inconel (slurry is $35 \mathrm{~g} \mathrm{NaCl}+100 \mathrm{~g}$ silica sand +1 litre water), there was $0.05 \%$ weight loss.

Note on the speed of impinging solid particles of slurry

Diameter of slurry pot (D) $=12.5 \mathrm{~cm}$

Velocity of particles $=\pi \mathrm{DN} / 60 \mathrm{~m} / \mathrm{s}$

Therefore, For $\mathrm{N}=1000 \mathrm{rpm}$,

Velocity of solid particles $=6.54 \mathrm{~m} / \mathrm{s}$ and

For $\mathrm{N}=500 \mathrm{rpm}$,

Velocity of solid particles $=3.27 \mathrm{~m} / \mathrm{s}$.

The influence of particle velocity on erosion rate can only be understood in terms of a quantitative model for slurry flow and particle impact and an assumption on the nature 
Fig.3 (b). Effect of coating thickness for rotational speed - 1000rpm

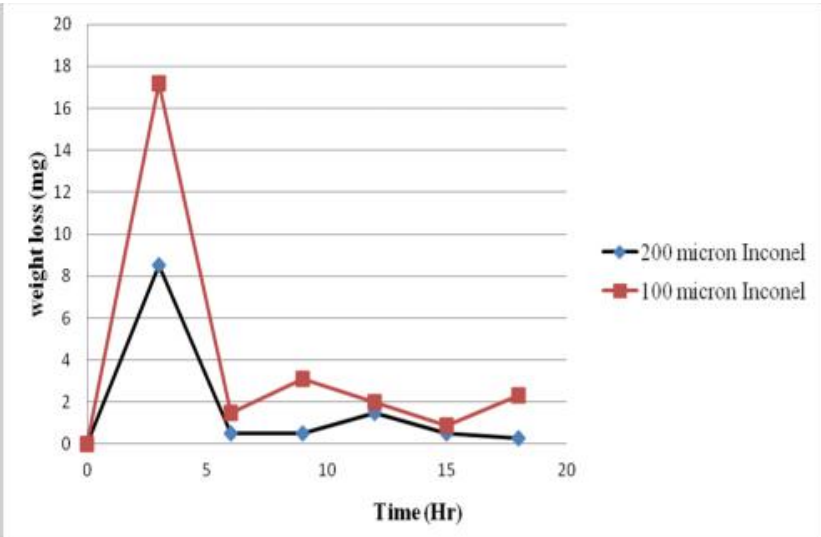

of the rate-controlling factor governing material loss (Particle velocity and size effect, October 2002).

Graphical interpretation of the results obtained

The Fig. 3(a). clearly shows the deviation in weight loss when tests are conducted with bare mild steel and mild steel coated with either Inconel $90 \%+10 \%$ Titania $50 \mu$ or Inconel $95 \%+5 \%$ Titania $200 \mu$. So when mild steel is not coated, the weight loss is much more when compared to the coated specimens. This proves our theory that erosion rate decreases with coating.

The Fig. 3(b) gives the comparison between the weight loss in $200 \mu$ thickness and that of $100 \mu$ thickness Inconel coated mild steel specimens. The plot clearly shows that for 200 micron thickness of coating, the erosive rate is much lesser when compared to 100 micron thickness Inconel coating. Hence this again approves the theory that erosion rate decreases with increase in coating thickness.

Increase in coating thickness results in porosity reduction which is a major factor affecting corrosion. Presence of porosity leads to higher extent of localized pitting which accelerates the material removal process during slurry erosion tests where the primary mechanism of material removal is corrosion.

Mathematical modelling of inconel coated specimens

The values obtained experimentally have to be compared with theoretical values. For this purpose, two important correlations have been used are (Milind Suryaji Patil, 2011).
a) $E_{r}=0.075$ *
$(\Theta){ }^{0.12 *}$
$\left(\mathrm{C}_{\mathrm{w}}\right)^{1.09 *(\mathrm{~V})^{3.55}}$
(d) $1.37 *$
$\left.(1 / \mathrm{HN})^{\mathrm{a}} \mathrm{b}\right) \mathrm{E}_{\mathrm{r}}=2.57^{*}(\mathrm{~V})^{2.56 *}\left(\mathrm{C}_{\mathrm{w}}\right)^{0.83 *}(\mathrm{~d})^{0.85}$

Where $E_{r}=$ erosive rate in $\mathrm{mm} /$ year

$\Theta=$ angle of impact in degrees $\left(90^{\circ}\right.$ since inclined wedges are not used to hold the specimen),

$\mathrm{C}_{\mathrm{w}}=$ concentration in \%

$\mathrm{V}=$ impact velocity in $\mathrm{m} / \mathrm{s}$

$\mathrm{d}=$ particle size in $\mathrm{mm}$,

$\mathrm{HN}$ - hardness number (VHN)

$\mathrm{a}=$ any arbitrary constant

As can be predicted from Fig. 4(a) there is a maximum error of $24 \%$ which is due to the deviation that takes place at 3hours after the experiment has carried out. This error can be reduced by including time as a parameter. The equation can be modified as
$\mathrm{E}_{\mathrm{r}}=2.57^{*}(\mathrm{~V})^{2.56}$
$\left(\mathrm{C}_{w}\right)^{0.83^{*}}(\mathrm{~d})^{0}$
(d) ${ }^{0.85 *}(1 / \mathrm{HN})^{\mathrm{a} *}(\mathrm{~T})^{\mathrm{b}}$

Where $T$ is the time factor added to converge the theoretical curve closer to the experimental curve. 'a' and

Fig. 4(a). Comparison of theoretical deductions with experimental results $(100 \mu$ Inconel - (rotational speed $1000 \mathrm{rpm})$, hardness of Inconel = $360 \mathrm{VHN}$ )

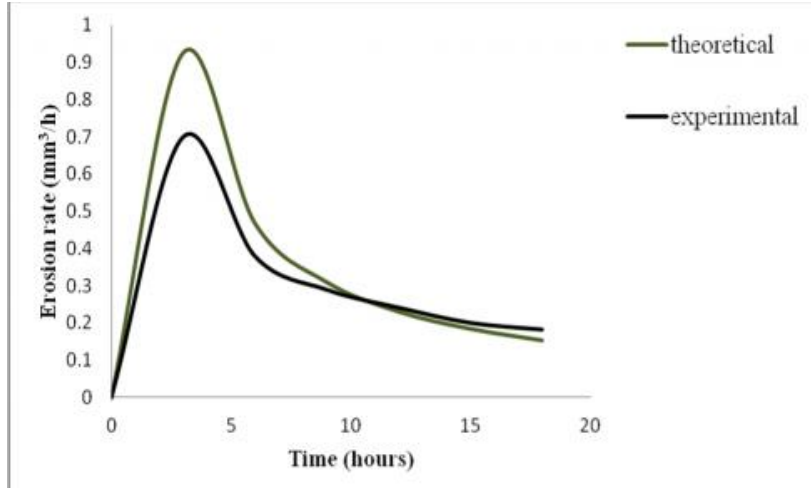

Fig. 4(b). Comparison of theoretical deductions with experimental results $(100 \mu$ Inconel $(1000 \mathrm{rpm})$ results when time was included as a parameter)

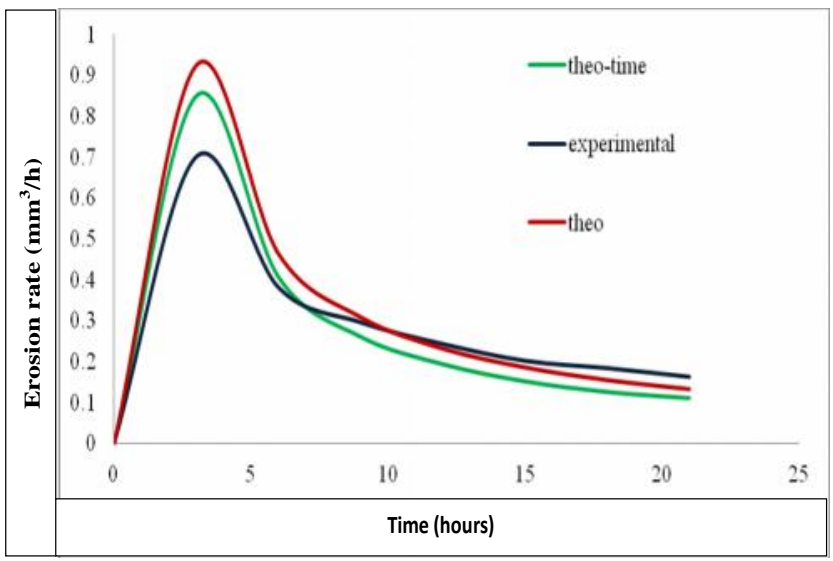

Fig .4(c). Comparison of theoretical deductions with experimental results $(200 \mu$ Inconel - (rotational speed -

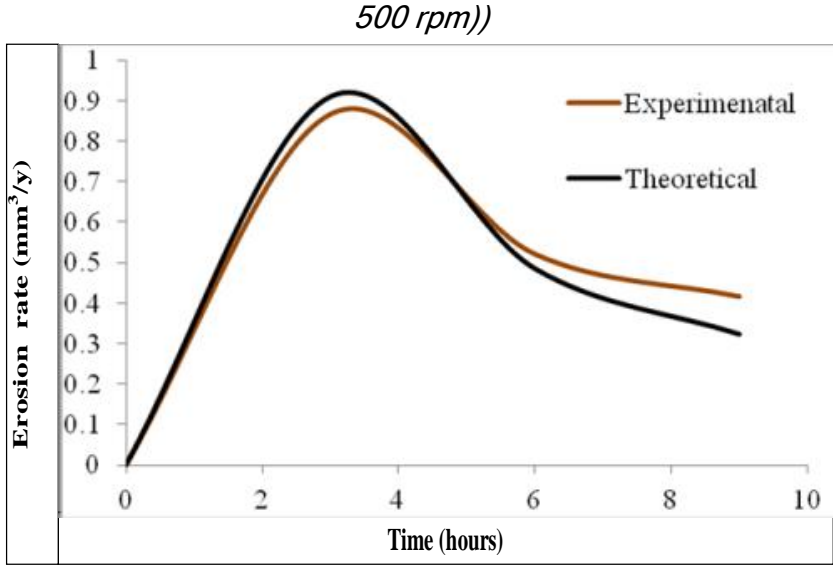

Research article

CCIndian Society for Education and Environment (iSee)
"Erosion resistant coating for steel" http://www.indjst.org
Sekhar et al. Indian J.Sci.Technol. 
'b' are arbitrary constants, $d=312 \mu \mathrm{m}$

The green curve in Fig 4(b) shows the improvement in results of theoretical values when time is taken (theo-time in $3.5 \mathrm{~b}$ ) as a parameter in the wear equation. The error is reduced from $24 \%$ to $18 \%$ at the peak (after 3 hours of experiment).

When the experiment is conducted for 200 micron thick Inconel coating on mild steel, and by taking hardness as a parameter, the theoretical values was closely matching with the experimental values with maximum error being $22.4 \%$ only as shown in Fig. 4(c).

Reduction in the number of parameters that affect the rate of erosion by non - dimensionalisation (Buckingham pi theorem)

As seen from the mathematical models above, Erosion rate or weight loss $\left(\mathrm{W}_{\mathrm{L}}\right)$ depends on a number of parameters such as velocity, particle size, hardness etc.

$W_{L}=f\left(v, d, H_{n}, t, t_{n}, \rho_{m}, \rho\right)$

$W_{L}=$ weight loss, $v=$ impact velocity, $d=$ particle size, $H_{n}$ $=$ Hardness number

$\mathrm{t}=$ duration of test, $\rho_{\mathrm{m}}$ is the density of the material (Inconel), $\rho$ is the density of silica, $t_{n}$ is the coating thickness

$\mathrm{W}_{\mathrm{L}}=\mathrm{f}\left(\mathrm{v}, \mathrm{d}, \mathrm{H}_{\mathrm{n}}, \mathrm{t}, \mathrm{t}_{\mathrm{n}}, \rho_{\mathrm{m}}, \rho\right)$

Non-dimensional variables ( $\Pi s)$ : (Young Donald, 2001)

Number of variables $(n)=8$, number of independent parameters $(\mathrm{k})=3$

Number of dimensionless parameters $=n-k=5$ and they are as follows:

$\Pi_{1}=\left(W_{L} / \rho v^{3} t^{3}\right)$

$\Pi_{2}=d / v . t$

$\Pi_{3}=t_{n} / v \cdot t$

$\Pi_{4}=H_{n} / v^{2} \rho$

$\Pi_{5}=\rho_{\mathrm{m} /} \rho$

Finally we arrive at $\Pi_{1}=f\left(\Pi_{2}, \Pi_{3}, \Pi_{4}, \Pi_{5}\right)$ or $W_{L} / \rho v^{3} t^{3}=$ $\mathrm{f}\left(\mathrm{d} / \mathrm{v} . \mathrm{t}, \mathrm{t}_{\mathrm{n}} / \mathrm{v} . \mathrm{t}, \mathrm{H}_{\mathrm{n}} / \mathrm{v}^{2} \rho, \rho_{\mathrm{m} /} \rho\right)$

Hence, from the Buckingham -pi theorem we infer that the number of parameters on which the weight loss $\left(\mathrm{W}_{\mathrm{L}}\right)$ depends is reduced from 7 to 4 and all the 4 parameters are dimensionless. By this method, the comparison of experimental and theoretical values becomes easier and the complexity of equation is reduced.

Refinement of plots using Matlab software (version 7.0)

Now from Buckingham pi theorem analysis, we have $\Pi_{1}=f\left(\Pi_{2}, \Pi_{3}, \Pi_{4}, \Pi_{5}\right)$.

Or, $\Pi_{1}=k^{*} \Pi_{2}{ }^{a} * \pi 3^{b *} n 4^{c *} n 5^{d}$. Taking natural logarithms on both sides, we have,

Loge $n 1=\log _{e} k+a \log _{e} \Pi 2+b \log _{e} \Pi 3+c \log _{e} \pi 4+d$ $\log _{\mathrm{e}} \mathrm{n} 5$ ( $\mathrm{k}$ is a constant and is taken equal to10)

An experiment was conducted from $0-15$ hours in intervals of 3 hours by coating mild steel with Inconel $95+$ 5 titania of $200 \mu$ thickness at a rotational speed of $1000 \mathrm{rpm}$ of the spindle. The experimental and theoretical plots were made. The maximum error was found out to be $91.2 \%$. For reducing this peak error, a matlab program was written to get a more refined theoretical formulation. The main aim of using matlab program is to obtain the most accurate values of the powers $a, b, c$ and $d$. Once the powers are obtained, a relation is obtained for weight loss $\left(\mathrm{W}_{\mathrm{L}}\right)$ and is compared with experimental values.

The program is as follows:

a=zeros $(7,5)$;

$\mathrm{p}_{\mathrm{m}}=2250$;

$\mathrm{t}_{\mathrm{n}}=200 \mathrm{E}-6$

$\mathrm{H}_{\mathrm{n}}=1118^{*} 10^{\wedge} 6$;

$\mathrm{v}=4.9$;

$\mathrm{p}=1250$;

$\mathrm{i}=0$;

$d=312^{*} 10^{\wedge}-6$;

$k=10$;

For $\mathrm{t}=10800: 10800: 54000$;

$\mathrm{i}=\mathrm{i}+1$;

$\mathrm{c} 1=\log (\mathrm{k})$;

$\mathrm{h} 2=\log \left(\mathrm{d} . /\left(\mathrm{v}^{*}{ }^{\mathrm{t}} \mathrm{t}\right)\right)$;

$\mathrm{h} 3=\log \left(\mathrm{t}_{\mathrm{n}} . /\left(\mathrm{v}^{*} \mathrm{t}\right)\right)$;

$\mathrm{h} 4=\log \left(\mathrm{H}_{\mathrm{n}} \cdot /\left(\mathrm{v} \cdot{ }^{\wedge} 2 .{ }^{*} \mathrm{p}\right)\right)$;

$\mathrm{h} 5=\log \left(\mathrm{p}_{\mathrm{m}} \cdot / \mathrm{p}\right)$;

$\mathrm{h}=[\mathrm{c} 1, \mathrm{~h} 2, \mathrm{~h} 3, \mathrm{~h} 4, \mathrm{~h} 5]$;

$\mathrm{a}(\mathrm{i},:)=\mathrm{h}$;

fprintf ('\%10.10f' ',a(i,:));

Fprintf ('In');

End

In the above program $\mathrm{h} 1, \mathrm{~h} 2, \mathrm{~h} 3, \mathrm{~h} 4, \mathrm{~h} 5$ are the nondimensional parameters or the n's

$\mathrm{p}_{\mathrm{m}}$ is the coating (Inconel + titania) density and $\mathrm{p}$ is the density of silica in $\mathrm{kg} / \mathrm{m}^{3}$. V is particle velocity in $\mathrm{m} / \mathrm{s}, \mathrm{t}_{\mathrm{n}}$ is coating thickness in $m$ and $H_{n}$ is the hardness of silica in Mpa.

This program when executed in the matlab software will give a $5^{\star} 5$ matrix which is pre-multiplied by the $\log \Pi_{1}$ matrix to obtain the column matrix containing the constant (c1) and the exponents ( $a, b, c$ and d). A formulation for weight loss is developed and was compared with the experimental values. The error was reduced from $91.2 \%$ to $19.37 \%$. This shows the stability or the refinement in the theoretical prediction got using Matlab software. The plots are as follows in Fig. 5.

Fig. 5. The stability or the refinement in the theoretical prediction got using Matlab software

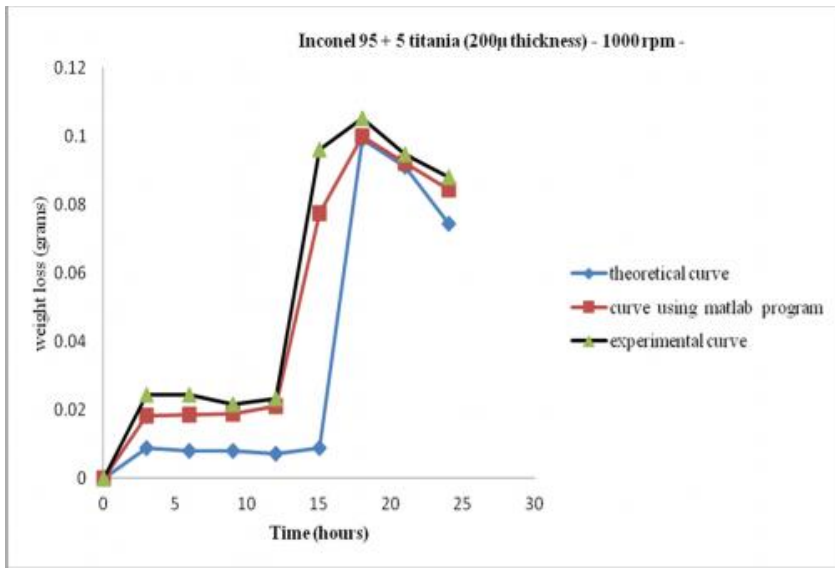

Research article

(C)Indian Society for Education and Environment (iSee)
"Erosion resistant coating for steel" http://www.indjst.org
Sekhar et al. Indian J.Sci.Technol. 


\section{Conclusions}

For the tests conducted at a rotational speed of 500 rpm and a slurry concentration of (35 grams $\mathrm{NaCl}+$ 100 grams silica sand +1 litre water), Mild steel coated with $95 \%$ Inconel $+5 \%$ titania (thickness $200 \mu$ ) offered greater resistance to slurry erosion. For the same slurry concentration, when the tests were conducted at 1000 $\mathrm{rpm}, 200 \mu$ Inconel offered greater resistance to slurry erosion when compared to $100 \mu$ Inconel. The size of solid particles impinging on the caoting is $312 \mu \mathrm{m}$ for both the speeds (500 and $1000 \mathrm{rpm})$.

For $1000 \mathrm{rpm}$ speed and a slurry concentration of $(35 \mathrm{~g}$ $\mathrm{NaCl}+100 \mathrm{~g}$ silica +1 litre water), theoretical prediction almost matches with experimental values for Inconel $100 \mu$ except at the peak with $24 \%$ error.

When time is introduced as a parameter for this specimen, the error dropped to $18 \%$ showing the effect of duration on wear test. Hence in the tests conducted, the effect of coating thickness and various parameters such as (duration, velocity, particle size, hardness) on slurry erosion has been studied. A non dimensional analysis using Buckingham- pi theorem was done on slurry erosive wear.

The analysis reduced the number of parameters on which the weight loss depended. The number of parameters influencing weight loss decreased from 7 t0 4 $\left(\Pi_{2}, \Pi 3, \pi 4, \pi 5\right)$ which can reduce the complexity of testing conditions. A program was typed in Matlab (version 7.0) for refining the curve of mild steel coated with Inconel 95 + 5 titania (200 micron thickness). The error was reduced from $91.2 \%$ to $19.37 \%$ which shows the stability of the program incorporated.

\section{Acknowledgements}

The authors wish to thank HOD, Mechanical Engineering Department, Principal and management of PESIT, Bangalore for encouragement and support.

\section{References}

1. Clarke H, Mci and Harwich Ryan B (2001) A reexamination of the particle size effect in slurry erosion. Wear. 248, 147-161.

2. Ernest John Teichert (1944) Introduction to ferrous metallurgy by, Pennsylvania State college. Tata McGraw Hill company, Inc.

3. Milind Suryaji Patil, Eknath R, Deore, Ramchandra S, Jahagirdar and Santosh V Patil (2011) Proc. World Congress on Engg. Study of the Parameters affecting erosion wear of ductile material in solid-liquid mixture. (pages 1-4)

4. Young Donald F (2001) A Brief Introduction to fluid mechanics second addition. John Wiley \& sons, Inc.

(Pages 240-250) 